interests to the author. I do not belong to this class, but am an interested worker in a neighbouring field who hoped to look over the hedge with interest and profit. In this I was a little disappointed. Birks himself says "Theory has been kept to the essential minimum", and while he is right not to repeat well known quantum theory, he does not use it much either. Paradoxically, the account would be easier really to comprehend if the concepts were less simply expressed. The simple perimeter free electron orbital model language chiefly used is less informative than state descriptions based on molecular point groups, especially when the former is introduced by figure $\mathbf{1 \cdot 4}$, where the idea of nodal planes seems to be applied to many electron states rather than to one electron orbital. And while spin-orbit coupling is all important in radiative and radiationless singlet-triplet transitions, the discussion is largely qualitative, the energy term appearing twice as $\mathrm{H}_{\text {so }}$ and never as $\zeta$ l.s. or more complicated expressions.

This, then, is an important new monograph for which all active in the field will thank the author for his clear display of the known facts. It is an essential purchase for all relevant libraries. In considering its suitability for students, young or old, I am driven in honesty to report that I felt my knowledge had been increased more than my real understanding.

D. H. WHIFFEN

\section{INTERNATIONAL MATHS}

\section{Mathematics Applied to Physics}

Edited by E. Roubine. Pp. xvii +610. (Springer-Verlag: Berlin and New York, 1970.) 58 DM; $\$ 16$.

A UNESCo sponsored congress on science teaching, held at Dakar in 1964, "agreed to recommend, as a priority measure, the preparation of a university syllabus of mathematics to meet the needs of physicists". This book is apparently the outcome of that decision, although it is clearly not a syllabus, being a collection of connected articles on various branches of mathematics, nor is it a textbook designed to meet the needs of such a syllabus, because several chapters are rather too concise to be easily followed by students quite unfamiliar with the material.

Each chapter is an admirably clear, up to date, and, in nearly every case, a readable account of its subject; chapter one confines itself to listing definitions and theorems; chapters four and ten are more restricted in scope than the rest and so are able to provide more leisurely treatments, even giving a few proofs; the remaining chapters find a compromise between these extremes. The chapters are largely independent of each other: the few cross-references give the impression of being afterthoughts.

The result of a collaboration between authors from seven countries, the book seems, perhaps inevitably, slightly uncertain of its level. To take a trivial example, it is not assumed that the reader knows what a differential equation is, although the term Hilbert space is used several times without definition.

The needs of physicists are seen in fairly classical terms: more than half of the book is devoted to differential equations. The final chapter, called "Quantum Mechanics", is considerably shorter than any of the others, and is, in fact, an elementary account of group representations and angular momentum in quantum mechanies.

If allowance is made for its classical emphasis, this book succeeds very well in providing a "syllabus plus some of the important details" covering the basic mathematical requirements of many branches of physics. It treats in an economical manner several important subjects, providing references to more detailed treatments where necessary, and so should also provide a useful work of reference.

\section{Short Notices}

Science, Industry and Society: Studies in the Sociology of Science. By S. Cotgrove and S. Box. Pp. xii +211. (Allen and Unwin: London, July 1970.) $50 s$ boards; $30 s$ paper.

A HACKNEYED phrase in the sociology of science is that nearly every scientist who has ever lived is alive today. Stephen Cotgrove and Steven Box inform us of that in the opening sentences of the cover notes, the preface and chapter one of their book. That is a pity, because the book contains a much more original insight into some of the problems currently being faced by scientists--the influences of industry on the universities, the satisfaction and dissatisfactions of working in a laboratory and the gulf between academic and industrial scientists. The basis of the book is a series of questionnaires sent to scientists in universities and in industry, and the facts are presented in a comprehensive if rather dull manner. Science, Industry and Society stands, however, alongside Stephen Cotgrove's Science of Society as an important contribution to the sociology of science.

SI Units and Conversion Tables: A Practical Guide for Scientists. By M. N. Hughes, A. M. James, and N. R. Silvester. Pp. 23. (Machinery: Brighton, 1970.) $4 s 6 d$.

THIs booklet is not designed to add more polemic to the discussion of the SI system but simply presents, in its uncompromising finality, a compilation of the symbols and units which constitute this system and the conversion factors relating it to its imperfect predecessors. The work seems to be aimed primarily at physicists and chemists, and yet anybody with editorial experience of the biological literature will know that the largest remaining concentration of the unconverted is to be found among the life scientists. This booklet should give them cause for introspection: not for long will they hold out against the schools on the one hand and technology on the other where the system is firmly implanted. One can comprehend but not condone the biologist's affection for units such as $\AA$, the Svedberg and $\mathrm{mmHg}$. With all respect, Angström and his colleagues Gauss, Maxwell, Oersted and others have had a good innings; surely even the biologists can be prevailed upon to acclaim the new presidium: Newton, Weber, Joule and. their friends.

Red Data Book. Vol. 5: Angiospermae. By R. Melville. (International Union for Conservation of Nature and Natural Resources Survival Service Commission: Morges, Switzerland, 1970.) SFr. 30; $\$ 7.00 ; 60 s$.

THE status of many threatened plants is so uncertain that the International Union for Conservation of Nature and Natural Resources has deemed it wise to publish before completion the latest volume of its catalogue of rare and vanishing species. As more information becomes available further sheets will be prepared for this looseleaf volume to add to the sixty-eight endangered angiosperms that Dr Melville has traced so far. Non-specialists need have no fear that this information will be beyond their comprehension; plants are described in the straightforward language of school botany. There are also, whenever possible, notes on distribution, habitat, biological value and so on. Remedial measures recommended include the preservation of Mount Athos in Greece as a national park free of grazing animals, so that Centaurea athoa, yellow Athos knapweed, may thrive again. 